\title{
Cost-effectiveness Analysis of Medication Safety Program at Pediatrics, Obstetrics and Gynecology Hospital, East Province, Saudi Arabia
}

\author{
Yousef Ahmed Alomi* iD, The \\ Former General Manager of General \\ Administration of Pharmaceutical Care, \\ Former Head, National Clinical Pharmacy \\ and Pharmacy Practice. Former Head, \\ Pharmacy R\&D Administration, Ministry of \\ Health, Riyadh, SAUDI ARABIA. \\ Amal Ahmad Alanazi, Medica- \\ tion Safety Officer, Pharmaceutical Care \\ Administration, Eastern Province, SAUDI \\ ARABIA. \\ Mohammed Mohsen Almaznai, \\ Director of Pharmaceutical Care Adminis- \\ tration in Eastern Province Health, SAUDI \\ ARABIA. \\ Fatimah Ali Albusalih, College of \\ Clinical Pharmacy, Imam Abdulrahman \\ Bin Faisal University (University of Dam- \\ mam) Dammam, SAUDI ARABIA.

\section{Correspondence:} \\ Dr. Yousef Ahmed Alomi, Former \\ General Manager of General Administration \\ of Pharmaceutical Care, Former Head, \\ National Clinical Pharmacy and Pharmacy \\ Practice, Former Head, Pharmacy R\&D \\ Administration, Ministry of Health, \\ Riyadh-11392, SAUDI ARABIA.
}

Phone no: +966 504417712

E-mail:yalomi@gmail.com
Received: 13-2-2019

Approved: 3-4-2019

Copyright: (c) the author(s),publisher and licensee Pharmacology, Toxicology and Biomedical Reports. This is an open-access article distributed under the terms of the Creative Commons Attribution NonCommercial License, which permits unrestricted non-commercial use, distribution, and reproduction in any medium, provided the original work is properly cited.

This is an open access article distributed under the terms of the Creative Commons Attribution-NonCommercial-ShareAlike 4.0 License

Access this article online

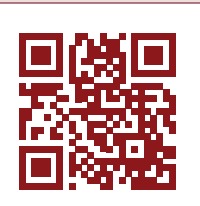

www.ptbreports.org

DOI:

10.5530/PTB.2019.5.31

\begin{abstract}
Objectives: Medication safety program initiated at East Province of Ministry of Health in 2013. The pharmacist prevents all drug related problems. To improve continuity of care at hospital admission, discharge and to diminution medication errors medication safety programs are established. The objective of this study was to evaluate the cost-effectiveness of the Medication Safety program at the hospital in East province, Saudi Arabia by using International Study Model. Methods: This cross-sectional study with a 12-month recruitment period was conducted in a 500-bed Pediatrics, Obstetrics and Gynecology Hospital through preventing and documentation of medication errors in adults and pediatrics at Ministry of Health hospitals in 2015. The hospital had medication safety officer with medication safety committee. The program led by trained pharmacist and delivered basic patient safety in medical education to all healthcare professionals. The expected cost calculated using International Study Model, expressed in United State Dollars (USD), the cost measured were the expected results of medication errors outcome if not stopped; starting from ambulatory care visit or community pharmacy, additional laboratory test, hospital or critical care admission or even death complications. Results: The total number of prevented medication errors were 2071 at 827 prescribed to 827 patients with an estimated cost avoidance of avoiding medication was (116,228.41 USD) annually. The most estimated cost avoidance was prescriber related and general errors was 99.12\% (115.201.9 USD). The pharmacist avoided medication errors with estimated cost avoidance of drug related problem (140.54 USD) per each prescription and (56.12 USD) per error. The most common categories of medications cost avoidance were Musculoskeletal and joint disease (8,397.2 USD) followed by Infections (5,731.17 USD) and Nutrition class (4,717.99 USD). The highest drug of cost avoidance were Insulin injection (39,964.32 USD), iron tablet (11,526.9 USD) folic acid tablet (11,526.9 USD) and calcium tablet (11,526.9 USD) and Enoxaparin injection (9,637.02 USD). There were three high-risk medication founded with Insulin, Enoxaparin and Heparin errors with (42.9\%) of annual total cost avoidance. Conclusion: Medication safety program is a cost-efficiency replication at Pediatrics, Obstetrics and Gynecology Hospital in Saudi Arabia, prevents medication misadventures, improve patient safety and education. Growing drug safety program related with preventing drug-related problems and cost avoidance replication for Healthcare improvement, better care and better patient consequences.
\end{abstract}

Key words: Cost, Efficiency, Medication, Safety, Ministry of Health, Pediatrics, Obstetrics and Gynecology, Saudi Arabia.

\section{INTRODUCTION}

The medication process is vulnerable and error prone as it is a composite five phase process: (a) prescribing, (b) verifying, (c) preparing/dispensing (d) administering and (e) monitoring. ${ }^{1}$ Rates of medication errors vary, depending on the detection method used. Estimates of the occurrence of Medication Errors (MEs) vary between 5\% and $25 \%$ of all medication administrations. The Error can be an error in drug selection, usage, dose, route of administration, quantity, indication or use in case of contraindication. ${ }^{2}$ The national patient safety agency (NPSA) likewise recommend a wide range of different definitions in medication errors recording, together with techniques for information buildup. In-hospital medication preparation and administration has been considered as 'high risk' area. The complementary surely understood "six Rights of the Medication Use Process" ought to dependably be: patient, drug, dose, route, time and outcomes. Exclusion as well as failure to check individuality of patients, with wrong administration technique or wrong dispensing or expired drug are considered administration errors. ${ }^{2}$

An instructive intercession program drove by the drug specialist was considered and connected. ${ }^{3}$ The assessment method for such program was finished by recognizing level of errors after intervention and before. ${ }^{4}$ Prescription errors have been characterized as "any preventable occasion that may cause or prompt wrong drug or patient damage under the supervision of the patient himself, a customer on his/her behalf or a health-care professional". ${ }^{5}$ There are additionally extraordinary frameworks for arranging prescription errors. Health care quality problems may be classified into 3 categories, underuse, overuse and misuse, which affect patients' health and wellbeing. Underuse is the failure to provide a health care service when it would have produced a promising result for a patient. Overuse occurs when a health care service is provided under conditions in which its potential for injury exceeds 
the possible advantage. Misuse occurs when an suitable service has been selected but a preventable complication occurs and the patient does not receive the full potential benefit of the service. ${ }^{6}$ Adverse Drug Events (ADEs) in hospitalized patients will outcome in longer hospital stays and extra medical expenses, even though they are sometimes unnecessary. On the other side, another researcher has grouped prescription errors into 4 classes based on their potential clinical results: ${ }^{7}$ type A (serious or potential seriousness); type B (significant annoyance drug specialist (either a pharmacist or a medical doctor) contact required); type C (minor disturbance - drug specialist must utilize proficient judgment); and type $\mathrm{D}$ which is called trivial.

The economics of medication safety program is seldom finding in the literatures especially in pediatrics population. Two international studies by Chen $\mathrm{C}$ et al. ${ }^{8}$ and Najafzadeh $\mathrm{M}$ et al. ${ }^{9}$ measured the economic impact and cost avoidance of the program. The studies showed the enhancement of the benefit-cost analysis from 4.29 to 9.36 , total cost avoidance was $103,073,160$ - 224,590,140 US \$ and average admission days decreased by 2 days after the on-ward deployment of a clinical pharmacist during the study period. Najafzadeh $\mathrm{M}$ et al. found $52 \%$ reduced of medication reconciliation discrepancies and total saved was 175,306 US \$ in the study period. ${ }^{9}$ Despite times of effort to progress quality and safety in health care, this goal feels progressively indefinable. To the best of our knowledge, no comprehensive scientific study has explored these challenges and barriers in all Healthcare Facilities (HCFs) across the Kingdom of Saudi Arabia (KSA). The objective of this study was to evaluate the cost-effectiveness of the Medication Safety program at the hospital in East province, Saudi Arabia by using International Study Model.

\section{METHODS}

This was a retrospective analysis of pharmacist intervention and prevented medication errors. This cross-sectional study with a 12-month recruitment period was conducted in a 500-bed Pediatrics, Obstetrics and Gynecology Hospital through preventing and documentation of medication errors in adults and pediatrics at Ministry of Health hospitals in 2015. The study included the hospital outpatient clinics and inpatient departments, ambulance as well as pharmaceutical preparation room, mixing intravenous solutions, all pediatrics and adults' patient during the conduct of the study. The routine work of an inpatient pharmacist consists of dispensing and reviewing medication orders. The hospital services cover a range of medical offerings from basic health care to Endocrinology Pediatrics, Hematology Pediatrics, Nephrology Pediatrics, Cardiology Pediatrics, Pulmonary Pediatrics, The Neonatal Intensive Care Unit (NICU), The Pediatric Intensive Care Unit, Obstetrics and Gynecology in addition to ambulatory care services and emergency services. Also, the hospital pharmacy offers very comprehensive pharmaceutical services including inpatient pharmacy, ambulatory care pharmacy, Total Parenteral Nutrition (TPN) services, drug information services and computerized physician order entry system inpatient and outpatient units. Also, the clinical pharmacist shared in the round with the medical team and patient counseling clinics. Medication safety program founded at East Province Region in 2013. ${ }^{10}$ National medication safety program of Ministry of Health and Central committee of medication committee it headed by first and second authorship and East Province Regional Medication safety committee headed by second author. In particular, a hospital medication safety program managed by part-time pharmacist and the program consisted of medication officer and local committee of medication safety.

The officer monitors all medication errors, adverse drug reaction, drug quality system inside the hospital according to local standard of accreditation body (Saudi Central Board of Health Care Accreditation) standards and medication safety of Joint commission of Hospital accreditation from United States of America. ${ }^{11,12}$ Beside, the implementations of the Institute Safety Medication Practice (ISMP) guidelines, ${ }^{13-16}$ They also felt accountable for medication safety course to all health care professional, physician, pharmacist, nurses etc. and report all medication safety related issues to higher administration and $\mathrm{MOH}$.

Medication officers are responsible for documenting Medications Errors (MEs) and Adverse Drug Events (ADEs) using the different forms. All errors or unforeseen events related with the medication system or a step in the medication process shall be reported using the medication error notification form/medication error sheet whether or not the error reached the patient. The medical error form consists of 2 parts and 40 items including types and causes of medical errors. The form mainly consisted of patient information, description of errors - date and time, medical product involved in the event, impact of the error, consequences, intervention, the sources of medication errors and qualification of committing errors. Suspected medications, drug classification, stage of medication orders, details of reporter, route of administration for medication, the type of medication errors, description and causes of errors, agreement to prevent the errors and the significance of medication errors by using National Coordinating Council for Medication Error Reporting and Prevention (NCCMERP) system. ${ }^{17}$ The expected cost calculated using International Study Model, expressed in USD, the cost measured were the expected results of medication errors outcome if not stopped; starting from ambulatory care visit or community pharmacy, additional laboratory test, hospital or critical care admission or even death complications. ${ }^{18,19}$ The format analyzed through the Microsoft Excel Sheet Version $10^{\text {th }}$. The study was conducted according to the ethics guidelines set out in the Declaration of Helsinki and written consent from was obtained from the institution.

\section{RESULTS}

The total number of prevented medication errors were 2071 at 827 prescribed to 827 patients with an estimated cost avoidance of avoiding medication was $(116,228.41$ USD) annually. The most estimated cost avoidance was prescriber related and general errors was $99.12 \%$ (115.201.9 USD), which include highly error in wrong abbreviation $86.27 \%$ (100,270.62 USD) and poor handwriting 12.63\% (14,681.37 USD) (Table 1 and 2). The pharmacist avoided medication errors with estimated cost avoidance of drug related problem (140.54 USD) per each prescription and (56.12 USD) per error. The highest cost avoidance founded in old young adults (40 - 65 years) $20.81 \%$ (23,977.99 USD) and young adults (18-40 years) $11.90 \%$ (13,833.2 USD) (Table 2 and 3 ).

The most common categories of medications cost avoidance were Musculoskeletal and joint disease (8,397.2 USD) followed by Infections (5,731.17 USD) and Nutrition class (4,717.99 USD). The highest drug of cost avoidance was Insulin injection (39,964.32 USD), iron tablet (11,526.9 USD) folic acid tablet (11,526.9 USD) and calcium tablet

Table 1: Type of medication errors vs documented cost avoidance.

\begin{tabular}{|l|c|c|c|}
\hline Type of Errors & Number & Cost (USD) & Percentages \\
\hline Patient-Related error & 426 & 0.00 & $0.00 \%$ \\
\hline $\begin{array}{l}\text { Prescriber-Related and general } \\
\text { errors }\end{array}$ & 1,633 & $115,201.90$ & $99.12 \%$ \\
\hline Drug-Related errors & 9 & 705.25 & $0.61 \%$ \\
\hline Dosage Form-Related Errors & 0 & 0 & $0.00 \%$ \\
\hline Therapeutics-Related Errors: & 3 & 321.26 & $0.28 \%$ \\
\hline Total cost & 2,071 & $116,228.41$ & $100.00 \%$ \\
\hline Total cost with $10 \%$ discount & & $104,605.57$ & \\
\hline Total cost with 20\% discount & & $92,982.73$ & \\
\hline
\end{tabular}


Table 2: The subtype of medication errors preventions vs documented cost avoidance.

\begin{tabular}{|c|c|c|c|}
\hline Subtype of medication errors & Number & Cost & Percentages \\
\hline \multicolumn{4}{|l|}{ Patient-Related error } \\
\hline Diagnosis not written & 426 & 0 & $0.00 \%$ \\
\hline Patient allergy & - & - & - \\
\hline Patient body weight not written & - & - & - \\
\hline Patient age not written & - & - & - \\
\hline Wrong patient & - & - & - \\
\hline Non- existing patient & - & - & - \\
\hline \multicolumn{4}{|l|}{$\begin{array}{l}\text { Prescriber-Related and general } \\
\text { errors }\end{array}$} \\
\hline $\begin{array}{l}\text { Prescriber name is missing / } \\
\text { unclear }\end{array}$ & - & - & - \\
\hline Prescriber ID\# is missing /unclear & - & - & - \\
\hline $\begin{array}{l}\text { Prescriber signature missing / } \\
\text { unclear }\end{array}$ & - & - & - \\
\hline $\begin{array}{l}\text { Prescriber not follow policy of } \\
\text { prescribing (write dose / weight) }\end{array}$ & 4 & 219.56 & $0.19 \%$ \\
\hline Wrong transcription & 1 & 30.35 & $0.03 \%$ \\
\hline Department is missing / unclear & - & - & - \\
\hline Poor handwriting & 561 & $14,681.37$ & $12.63 \%$ \\
\hline Wrong abbreviations & 1067 & $100,270.62$ & $86.27 \%$ \\
\hline Prescription data unclear & - & - & - \\
\hline \multicolumn{4}{|l|}{ Drug-Related errors } \\
\hline Incorrect dose-overdosing & 6 & 565.91 & $0.49 \%$ \\
\hline Dose omitted & 1 & 109 & $0.09 \%$ \\
\hline Duration-inadequate & - & - & - \\
\hline Dosing frequency-excessive & 1 & 30.35 & $0.03 \%$ \\
\hline Incorrect dose-under dosing & - & - & - \\
\hline $\begin{array}{l}\text { Amount of drug missing / unclear } \\
\text { / insufficient }\end{array}$ & - & - & - \\
\hline Drug name is missing /incorrect & - & - & - \\
\hline Duration-excessive & - & - & - \\
\hline Dosing frequency-inadequate & - & - & - \\
\hline Incorrect drug & - & - & - \\
\hline \multicolumn{4}{|l|}{ Dosage Form-Related Errors } \\
\hline Incorrect /unclear formulation & - & - & - \\
\hline Incorrect / unclear route & - & - & - \\
\hline Incorrect / unclear strength & - & - & - \\
\hline \multicolumn{4}{|l|}{ Therapeutics-Related Errors } \\
\hline Drug-drug interaction & - & - & - \\
\hline Drug-Disease interaction & - & - & - \\
\hline Therapeutic duplication & 2 & 60.7 & $0.05 \%$ \\
\hline IV preparation without label & 1 & 260.46 & $0.22 \%$ \\
\hline
\end{tabular}

(11,526.9 USD) and Enoxaparin injection (9,637.02 USD). There were three high-risk medication founded with Insulin, Enoxaparin and Heparin errors with (42.9\%) of annual total cost avoidance (Table 4 and 5).
Table 3: Age distribution vs documented cost avoidance.

\begin{tabular}{|l|c|c|c|}
\hline Answer Options & $\begin{array}{c}\text { Response } \\
\text { Count }\end{array}$ & Cost (USD) & $\begin{array}{c}\text { Average cost per } \\
\text { patient for each } \\
\text { stage }\end{array}$ \\
\hline 30 Days & 8 & 204.09 & $0.18 \%$ \\
\hline 1 month - 6 years & 27 & 993.25 & $0.85 \%$ \\
\hline 6 - 12 years & 35 & $2,544.78$ & $2.19 \%$ \\
\hline 12 -18 years & 27 & $1,188.9$ & $1.02 \%$ \\
\hline 18 - 40 years & 158 & $13,833.2$ & $11.90 \%$ \\
\hline 40 - 65 years & 156 & $23,977.99$ & $20.81 \%$ \\
\hline more than 65 years & 31 & $2,484.7$ & $2.14 \%$ \\
\hline Answered question & 442 & & \\
\hline Skipped question & 363 & & \\
\hline
\end{tabular}

Table 4: Medication classes vs documented cost avoidance.

\begin{tabular}{|c|l|c|c|}
\hline No & Medication classes & $\begin{array}{c}\text { No of occurrences } \\
\text { medication had } \\
\text { errors }\end{array}$ & $\begin{array}{c}\text { Cost } \\
\text { avoidance } \\
\text { (USD) }\end{array}$ \\
\hline 1 & Musculoskeletal and joint disease & 60 & $8,397.2$ \\
\hline 2 & Infections & 88 & $5,731.17$ \\
\hline 3 & Nutrition & 41 & $4,717.99$ \\
\hline 4 & Gastrointestinal & 37 & $1,782.6$ \\
\hline 5 & Cardiovascular & 44 & $1,295.44$ \\
\hline 6 & Immunological products and & 13 & $1,089.44$ \\
\hline 7 & vaccines & 7 & 240.62 \\
\hline 8 & Central nervous system & 11 & 224.45 \\
\hline 9 & Endocrine system & 9 & 254.8 \\
\hline 10 & Ear, Nose and oropharynx & 2 & 56.52 \\
\hline 11 & urinary tract disorders & 2 & 26.17 \\
\hline & Total & 314 & \\
\hline
\end{tabular}

\section{DISCUSSION}

Although pharmacist-led medication reconciliation diminishes medication errors that commonly occur after hospital release, its economic value has not been entirely evaluated. In this study, we tried to evaluate cost-efficiency of medication safety program in pediatrics, obstetrics and gynecology hospital in East Province, Saudi Arabia. This is old method with new applications to detect, resolve, and prevent medication errors with medication-related problems.

The cost avoidance of medication safety program with emphasis on prevention of medication error was high and similar what reported by Chen $\mathrm{C}$ et al. ${ }^{8}$ There were an average cost avoidance available in the literature due to different methods of cost calculations and the different estimated method of cost avoidance. ${ }^{9}$ In the study, the most cost avoidance founded prescribing stage because the majority of medical errors were related to the prescribing stage (prescriber related medication errors). During this period, the hospital did not implement e-prescribing, drug altering system or clinical decision support system to prevent medication errors. As compared to handwritten prescriptions, computerized prescriptions seemed to be related with relatively lesser rates of error. This study estimated the cost avoidance of medication errors reported by pharmacists using an improved shared viewpoint. The medication safety 
Table 5: Top twenty medications involved prevention of errors VS documented cos avoidance.

\begin{tabular}{|c|l|c|}
\hline No & Medication & Cost \\
\hline 1 & Insulin inj & $39,964.32$ \\
\hline 2 & Iron tab & $11,526.9$ \\
\hline 3 & Folic acid tab & $11,526.9$ \\
\hline 4 & Calcium tab & $11,526.9$ \\
\hline 5 & Enoxaparin inj & $9,637.02$ \\
\hline 6 & Normal saline drop & $6,586.80$ \\
\hline 7 & Paracetamol syp & $5,757.4$ \\
\hline 8 & Chloropheniramine syp & $4,448.9$ \\
\hline 9 & Paracetamol supp & $4,226.53$ \\
\hline 10 & Oral rehydration solution & $2,909.17$ \\
\hline 11 & Amoxacillin/Clavulanic acid susp & $2,381.47$ \\
\hline 12 & Diphenhydramine syp & $1,648.71$ \\
\hline 13 & Cholecalciferol drop & 933.13 \\
\hline 14 & Pseudoephedrine and Triprolidine syp & 603.79 \\
\hline 15 & Gentamycin inj & 424.93 \\
\hline 16 & Gentamycin eye drop & 340.21 \\
\hline 17 & Heparin inj & 260.46 \\
\hline 18 & Salbutamol Buff & 219.56 \\
\hline 19 & Pipracillin/Tazobactam inj & 218 \\
\hline 20 & Amoxacillin susp & \\
\hline & & \\
\hline
\end{tabular}

pharmacist services have significant clinical benefits to patients and substantiate the greatest cost savings for healthcare budgets. Prevented errors were higher in patients with more ages because they used very critical and high-risk medications and any error, may be associated with an increased risk of hospitalization or permanent disability or critical admission or even death related complications.

The highest cost avoidance related class of medications was muscular and joint disease because the drug therapy of the disease had several complications especially for pain management for instant non-steroidal antiflammatory medications. The common types of error associated with antibiotics or antiviral medications were dosing related issues. The findings demonstrated that the highest drug of cost avoidance was Insulin injection, iron, calcium and folic acid tablet (maternity cases) and Enoxaparin injection. Another highest class of medications in cost avoiding of prevention medications errors in pediatrics populations was nutrition medications like Total Parenteral Nutrition (TPN) similar to previous study reported by Alomi YA et al. ${ }^{20}$ Some high-risk medications occurred during committing errors in current study for insulin or heparin because their complications and economic burden are high.

The most of findings of current research were problematic to compare with other investigations because rarely existed of research variables and to the best of our knowledge, there is no study relating to this. The economic impact is very high in the study and the expanding pharmacist role is essential to include all drug distribution system in the hospital. Studies have constantly established that pharmacists contribute to reductions in costs in a wide variety of healthcare surroundings. The healthcare insurance companies should utilized the pharmacy to avoid un-necessary economic burden on healthcare system with implementation of new vision $2030 .{ }^{21}$ Factors other than the intervention cost might limit the execution of medication reconciliation. The clinical Pharmacist or distributive pharmacist showing this intervention must have access to precise and timely information about inpatient and outpatient medications. Most of the patient's viewpoint, results of complications of drug-related problems resemble what published in the other investigations with different practice.

\section{CONCLUSION}

Medication safety program is a cost-efficiency replication at Pediatrics and Obstetrics and Gynecology Hospital in Saudi Arabia, prevents medication misadventures, improve patient safety. Increasing drug safety program associated with preventing drug-related problems and cost avoidance replication for Healthcare improvement, better care and better patient consequences. High-quality economic evaluations with healthy methodologies and study design are required to explore what pharmacist services have noteworthy clinical benefits to patients and verify the greatest cost savings for healthcare budgets.

\section{ACKNOWLEDGEMENT}

None.

\section{CONFLICT OF INTEREST}

The authors declare no conflict of interest.

\section{ABBREVIATIONS}

MEs: Medication Errors; ADRs: Adverse Drug Reactions; NPSA: National Patient Safety Agency; NICU: Neonatal Intensive Care Unit; TPN: Total Parenteral Nutrition; MOH: Ministry of Health; ISMP: Institute Safety Medication Practice; NCC: National Coordinating Council; MERP: Medication Error Reporting and Prevention; KSA: Kingdom of Saudi Arabia; USD: United State Dollars.

\section{ORCID ID}

Yousef Ahmed Alomi, https://orcid.org/0000-0003- 1381-628X

\section{REFERENCES}

1. Word Health Organization. Safety of medicines: A guide to detecting and reporting adverse drug reactions. WHO Publ. 2002;1-18. Cited 2018 Oct 31 Available from: http://apps.who.int/medicinedocs/en/d/Jh2992e/

2. Williams DJP. Medication errors. J R Coll Physicians Edinb. 2007;73(4):343-6.

3. Bobb A, Gleason K, Husch M, Feinglass J, Yarnold PR, Noskin GA. The epidemiology of prescribing errors: The potential impact of computerized prescriber order entry. Arch Intern Med. 2004;164(7):785-92.

4. Peeters MJ, Pinto SL. Assessing the impact of an educational program on decreasing prescribing errors at a university hospital. J Hosp Med. 2009;4(2):97-101.

5. Pharmacopeia US. The United States Pharmacopeial Convention. 2018. Available from: http://www.usp.org/.

6. Chassin MR, Galvin RW. The urgent need to improve health care quality: Institute of Medicine National Roundtable on Health Care Quality. JAMA 1998;280(11):1000-5.

7. Neville RG, Robertson F, Livingstone S, Crombie IK. A classification of prescription errors. J R Coll Gen Pract. 1989;39(320):110-2

8. Chen CC, Hsiao FY, Shen LJ, Wu CC. The cost-saving effect and prevention of medication errors by clinical pharmacist intervention in a nephrology unit. Medicine. 2017;96(34):e7883.

9. Najafzadeh M, Schnipper JL, Shrank WH, Kymes S, Brennan TA, Choudhry NK. Economic value of pharmacist-led medication. Am J Manag Care. 2016;22(10):654-61.

10. Alomi YA. National Medication Safety Program at Ministry of Health in Saudi Arabia. J Pharmacovigil. 2015;3(5):e145.

11. Medication Management. In: National Hospital Standards. $2^{\text {nd }}$ Edn. Saudi Central Board for Accreditation of Healthcare Institutions. 2015;194-211.

12. The Joint Commission. Comprehensive Accreditation Manual for hospitals. Joint Commission Resources. 2016. Available from: http://www.mitsstools.org/ uploads/3/7/7/6/3776466/psc_for_web.pdf.

13. Adams AJ, Hauser RB, Kayden C, Landis W, McAntee S, McDermott J, et al. ISMP Medication Safety Self Assessment ${ }^{\circledR}$ for Community/Ambulatory Pharmacy. Medication Safety Self Assessment for Antithrombotic Therapy. 2017;1-35. 
Available from: https://www.ismp.org/sites/default/files/attachments/2018-01/ ISMP117C-Pharma\%20SA-FINAL\%20020317.pdf.

14. Institute for Safe Medication Practices. ISMP Medication Safety Self Assessment for Hospitals, Key Definitions. 2011;1-4. Available from: http://ismp.org/ selfassessments/Hospital/2011/definitions.pdf

15. ISMP International Medication Safety Self Assessment ${ }^{\circledR}$ for Oncology. 2012;1-7. Available from: https://www.ismp.org/assessments/international-oncology.

16. Conners J, Dager W, Evan M, Gulseth M, Jenkins RWM. ISMP Medication Safety Self Assessment for Antithrombotic Therapy. Institute for Safe Medication Practices. 2017. Available from: https://www.ismp.org/sites/default/files/attachments/2017-11/2017_ISMP_Antithrombotic_Self_Assessment.pdf.

17. Hartwig SC, Denger SD, Schneider PJ. Severity-indexed, incident report-based medication error-reporting program. Am J Hosp Pharm. 1991;48(12):2611-6.
18. Ling JM, Mike LA, Rubin J, Abraham P, Howe A, Patka J, et al. Documentation of pharmacist interventions in the emergency department. Am J Heal Pharm. 2005;62(17):1793-7.

19. Mutnick AH, Sterba KJ, Peroutka JA, Sloan NE, Beltz EA, Sorenson MK. Cost savings and avoidance from clinical interventions. Am J Heal Pharm. 1997;54(4):392-6.

20. Alomi YA, Fallatah AO, Al-Smail EH. Assessment of clinical and economic outcomes of pharmacist intervention in total parenteral nutrition program in Saudi Arabia. Value Heal. 2016;19(7):A465.

21. Alomi YA, Alghamdi SJ, Alattyh RA, Elshenawy RA. The evaluation of pharmacy strategic plan in past 2013-2016 and forecasting of new vision 2030 at Ministry of Health in Saudi Arabia. J Pharm Pract Community Med. 2018;4(2):93-101. 